\title{
Aqueous-phase photochemical oxidation and direct photolysis of vanillin - a model compound of methoxy phenols from biomass burning
}

\author{
Y. J. Li ${ }^{1}$, D. D. Huang ${ }^{2}$, H. Y. Cheung ${ }^{1}$, A. K. Y. Lee ${ }^{3}$, and C. K. Chan ${ }^{1,2}$ \\ ${ }^{1}$ Division of Environment, Hong Kong University of Science and Technology, Hong Kong, China \\ ${ }^{2}$ Department of Chemical and Biomolecular Engineering, Hong Kong University of Science and Technology, Hong Kong, \\ China \\ ${ }^{3}$ Department of Chemistry, University of Toronto, Toronto, Canada \\ Correspondence to: C. K. Chan (keckchan@ust.hk)
}

Received: 10 October 2013 - Published in Atmos. Chem. Phys. Discuss.: 25 October 2013

Revised: 7 January 2014 - Accepted: 13 February 2014 - Published: 19 March 2014

\begin{abstract}
We present here experimental results on aqueousphase (A) photochemical oxidation (with $\mathrm{UV}$ and $\mathrm{OH}$ radicals generated from $\mathrm{H}_{2} \mathrm{O}_{2}$ photolysis) and (B) direct photolysis (with only UV irradiation) of a methoxy phenol, vanillin (VL), as a model compound from biomass burning. Both on-line aerosol mass spectrometric (AMS) characterization and off-line chemical analyses were performed. AMS analyses of dried atomized droplets of the bulk reacting mixtures showed that VL almost entirely evaporates during the drying process. Large amounts of organic mass remained in the particle phase after reactions under both conditions. Under condition (A), AMS measured organic mass first increased rapidly and then decreased, attributable to the formation of non-volatile products and subsequent formation of smaller and volatile products, respectively. The oxygen-tocarbon $(\mathrm{O}: \mathrm{C})$ ratio of the products reached 1.5 after about $80 \mathrm{~min}$, but dropped substantially thereafter. In contrast, organic mass increased slowly under condition (B). The O : C ratio reached 1.0 after $180 \mathrm{~min}$. In off-line analyses, small oxygenates were detected under condition (A), while hydroxylated products and dimers of VL were detected under condition (B). Particle hygroscopic growth factor (GF) and cloud condensation nuclei $(\mathrm{CCN})$ activity of the reacting mixtures were found to depend on both organic volume fraction and the degree of oxygenation of organics. Results show that (1) aqueous-phase processes can lead to the retention of a large portion of the organic mass in the particle phase; (2) once retained, this portion of organic mass significantly
\end{abstract}

changes the hygroscopicity and CCN activity of the aerosol particles; (3) intensive photochemical oxidation gave rise to an $\mathrm{O}: \mathrm{C}$ ratio as high as 1.5 but the ratio decreased as further oxidation led to smaller and more volatile products; and (4) polymerization occurred with direct photolysis, resulting in high-molecular-weight products of a yellowish color. This study demonstrates that aqueous-phase reactions of a methoxy phenol can lead to substantial amount of secondary organic aerosol (SOA) formation. Given the vast amount of biomass burning input globally, model representation of either the SOA budget or their subsequent effects would not be adequate if the contribution of SOA formation from aqueousphase reactions of methoxy phenols is not considered.

\section{Introduction}

Reduction in saturation vapor pressure during chemical reactions, either by increasing the degree of oxygenation as in oxidation or increasing molecular weights as in polymerization (Kroll and Seinfeld, 2008), is the key to secondary organic aerosol (SOA) formation. Current models tend to underestimate the amount of SOA production (Heald et al., 2005). To close the gap, recent investigations have been searching for either missing precursors or mechanisms (Carlton et al., 2009) that would lead to products with substantially lower saturation vapor pressures than their precursors. Consideration of intermediately volatile organic compounds (IVOCs) 
as the missing SOA precursors (Donahue et al., 2006; Robinson et al., 2007) can possibly explain part of the underestimation. However, current studies have focused almost exclusively on the fossil-fuel-related long-chain alkanes in the IVOC range (Presto et al., 2010), which are precursors with no oxygen atoms in their structures. Some partially oxidized organic compounds whose saturation vapor pressures also fall in the IVOC range have not been adequately investigated. As for missing mechanisms, aqueous-phase oxidation has been advocated to be an important contributor to SOA in conditions where cloud, fog or wet aerosol particles are present (Blando and Turpin, 2000). There are numerous studies on aqueous-phase reactions but their focus has been limited to small aldehydes such as glyoxal and glycolaldehyde (Ervens et al., 2011), and recently pinene oxidation products (Lee et al., 2011).

Biomass burning is an important source of primary organic aerosol (POA) (de Gouw and Jimenez, 2009). It is also a source of SOA precursors (Cubison et al., 2011; Grieshop et al., 2009) because of the numerous organic compounds with a wide range of volatilities emitted. Cellulose, hemicellulose, and lignin are major constituents of biomass, and biomass burning organic aerosol (BBOA) still carries some signatures linking to these phyto-macromolecules even after extensive thermal degradation. Levoglucosan from cellulose or hemi-cellulose and methoxy-phenolic compounds from lignin have been used as markers of BBOA for a long time (Simoneit, 2002). As an abundant BBOA component and a well-known BBOA marker, levoglucosan was believed to largely exist in the particle phase, but recent studies have suggested that it is semi-volatile, and its stability is being questioned because it can partition back to the gas phase for photochemical aging (Hennigan et al., 2010) and can also be oxidized in aqueous phase (Hoffmann et al., 2009). On the other hand, phenols and methoxy phenols can contribute to $20-40 \%$ of particulate mass from burning hardwood and softwood (Hawthorne et al., 1989). Some methoxy-phenolic compounds will partition between the gas phase and the particle phase due to their relatively high saturation vapor pressures. For example, vanillin $\left(\mathrm{C}_{8} \mathrm{H}_{8} \mathrm{O}_{3}\right.$, 4-hydroxy-3methoxybenzaldehyde, CAS\#121-33-5) has a saturation vapor pressure of $1.18 \times 10^{-4} \mathrm{~mm} \mathrm{Hg}$ at $298 \mathrm{~K}$ (Yaws, 1994), equivalent to a saturation concentration of approximately $10^{3} \mu \mathrm{g} \mathrm{m}^{-3}$, and belongs to the IVOC range (Donahue et al.,

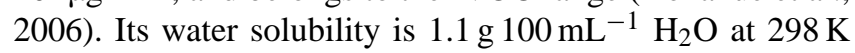
(Budavari et al., 1996), which puts it in the slightly water soluble category. The physical Henry's law constant of vanillin is thus estimated to be $4.65 \times 10^{5} \mathrm{M} \mathrm{atm}^{-1}$ at $298 \mathrm{~K}$ (Yaws, 1994 ), which is very close to the effective Henry's law constant of glyoxal (Ip et al., 2009). This means that vanillin, like glyoxal, will preferably be in the condensed phase if liquid water is available. In fact, it was observed that the efficiency with which fog water scavenges methoxy-phenolic volatile compounds such as vanillin was higher than $90 \%$ (Collett et al., 2008). Unlike glyoxal which self-polymerizes more fa- vorably than evaporates, vanillin is driven to the gas phase upon water evaporation (see discussions later). Upon dilution in the atmosphere, the intermediately volatile or semivolatile species such as vanillin in fine particles will at least partly evaporate, controlled presumably by absorptive partitioning. If coarse-mode droplets bearing a large amount of liquid water are available, the vapor-phase vanillin is then able to dissolve into the large droplets because of its slight solubility in water, resulting in a bimodal distribution. Indeed, this bimodal distribution of vanillin was clearly observed in a recent study (Wang et al., 2011).

We present experimental results of aqueous-phase reactions of a methoxy-phenolic model compound, vanillin, under two conditions: (A) UV $(254 \mathrm{~nm})+\mathrm{H}_{2} \mathrm{O}_{2}$ and (B) UV $(254 \mathrm{~nm})$ only. The aqueous bulk reacting mixture was partially atomized and dried for on-line analyses. The experimental setup, resembling a cloud-phase reaction/evaporation process, allowed us to characterize the evolution of organics in both the bulk aqueous solution and the particulate organics that remained after drying. The organics in the particles and in the solution during reactions were characterized by online aerosol mass spectrometry (AMS) and off-line analyses, respectively. Vanillin evaporated, as noted above, but large amounts of organic mass retained after reactions under both conditions (A) and (B), indicating the ability to retain slightly volatile organic species in the particle phase by aqueousphase reactions. Substantial differences in product identities and reaction kinetics were observed between these two conditions. Furthermore, the water uptake ability and cloud condensation activity were also monitored with a hygroscopic tandem differential mobility analyzer (HTDMA) and a cloud condensation nuclei counter $(\mathrm{CCNc})$. The hygroscopicity of particles after reactions was significantly altered, and will be discussed in conjunction with the degree of oxygenation of particulate organics at different time of the reactions.

\section{Experimental}

\subsection{Aqueous-phase reaction and control experiments}

The reaction apparatus was modified from Lee et al. (2011) and is shown in Supplement Fig. S1. A TSI 3076 constant output atomizer was modified to include: (a) a low-pressure mercury UV (254 nm) lamp (Pen-Ray, UVP, Canada); (b) a circulating sample collection system; (c) a magnetic stirrer; and (d) a water bath with an aluminum foil cover to keep out natural light during the experiments. A volume of $300 \mathrm{~mL}$ aqueous solution of $0.1 \mathrm{mM}$ ammonium sulfate (AS, Sigma, $\geq 99.0 \%$ ) and $0.1 \mathrm{mM}$ vanillin (VL, Sigma-Aldrich, $99 \%$ ), with or without $11.8 \mathrm{mM} \mathrm{H}_{2} \mathrm{O}_{2}$ (Sigma-Aldrich, 34.5$36.5 \mathrm{wt} \%$ ) was continuously atomized with compressed air to generate particles, which passed through a diffusion drier (BMI, Haywood, CA, USA) before going into the AMS, HTDMA and CCNc. The conditions and measurements in 
control (C_1 to C_4) and actual experiments (A_1 to A_9 and $B \_1$ to $\left.B \_7\right)$ are shown in Table 1. In some experiments (A_9 and B_7), aqueous solution samples were collected at different time intervals for off-line analyses. In the control experiments with AS only and the UV lamp on (C_1), AS and $\mathrm{H}_{2} \mathrm{O}_{2}$ with the UV lamp on (C_2), AS and VL without UV (C_3), and AS, VL and $\mathrm{H}_{2} \mathrm{O}_{2}$ without UV (C_4), the mass fractions of organics were normally less than $5 \%$ after drying, with the rest of particle mass being AS. The concentrations of sulfate, ammonium and organics, as well as the ratios of organics to sulfate in those control experiments without any one of the critical elements ( $\mathrm{UV}, \mathrm{H}_{2} \mathrm{O}_{2}$, or $\mathrm{VL}$ ) of the reactions are showed in Fig. S2. Results from experiments C_1 and C_2 showed that the mass contribution from the background (water) was negligible. Results from experiment C_3 indicated that VL evaporated almost completely during drying if no reaction occurred and those from experiment C_4 indicated that there was little retainable product formed between $\mathrm{VL}$ and $\mathrm{H}_{2} \mathrm{O}_{2}$, or the reaction between them is too slow for the timescale of the experiments $(3 \mathrm{~h})$.

\subsection{AMS analysis}

The high-resolution time-of-flight aerosol mass spectrometer (HR-ToF-AMS) has been described in detail elsewhere (DeCarlo et al., 2006). Briefly, particles leaving the diffusion dryer enter a set of aerodynamic lens for particle focusing and a particle time-of-flight (pToF) chamber for sizing. They then arrive at a heater with a temperature of $600^{\circ} \mathrm{C}$ for vaporization. Vapors of the non-refractory (NR) components are then ionized by electrons emitted by a tungsten filament. Ions are then transmitted to an ion time-of-flight (iToF) chamber for mass analysis and finally detected by a multi-channel plate (MCP) detector. In all the experiments, the HR-ToF-AMS was operated under two modes, each for 2 min. The first mode was operated under a V-shaped iToF (for lower mass resolving power but with higher sensitivity) plus pToF (for sizing). The second mode was operated under a W-shaped iToF (for higher mass resolving power but with lower sensitivity). The AMS data were analyzed using two toolkits, SQUIRREL and PIKA (Sueper, 2012), which are based on Igor Pro (Wavemetrics, Lake Oswego, OR). Based on previous studies (Li et al., 2011b; Zhang et al., 2005), the fragmentation table was modified for $m / z 18$ (or $\mathrm{H}_{2} \mathrm{O}^{+}$ion in $\mathrm{W}$ mode) and $\mathrm{m} / \mathrm{z} 28$ (or $\mathrm{CO}^{+}$ion in the $\mathrm{W}$ mode) for organics. Details of the modification can be found in the Supplement (Sect. 3.1, Fig. S4 and Table S1). Background mass spectra from control experiment C_1 (Sect. 3.2 in the Supplement) were also subtracted from mass spectra of experiments to obtain representative AMS mass spectra of the particle-phase organics formed during reactions (see Sect. 3.1 below). The AMS measures organics, sulfate, ammonium, nitrate and chloride. Nitrate and chloride in our experiments were negligible as expected. We do not exclude the possibility of organic sulfate formation during our exper- iments. However, due to the high temperature $\left(600^{\circ} \mathrm{C}\right)$ and high energy ionization, even if they were present, organic sulfates were likely fragmented to give sulfur-containing ions that are similar to inorganic sulfate, and was mostly counted as inorganic sulfate contribution. Therefore, the sulfate content is considered to be constant in the bulk solution during the experiments and will be used to normalize the measured organic content (Lee et al., 2012). Any fluctuations in the measured sulfate content were assumed to be due to the fluctuations in particle generation and the difference in collection efficiency (CE) as a result of the different organic contents of particles (Middlebrook et al., 2012).

\subsection{OH concentration estimation}

Under condition (A), $\mathrm{H}_{2} \mathrm{O}_{2}$ photolysis was used to generate $\mathrm{OH}$ radicals. In the $\mathrm{H}_{2} \mathrm{O}_{2}$ decay experiments, $\mathrm{H}_{2} \mathrm{O}_{2}$ concentrations were measured at different time intervals using a colorimetric method (Allen et al., 1952). A typical calibration curve is shown in Fig. S5. The decay rate $\left(k_{\mathrm{obs}}\right)$ of $\mathrm{H}_{2} \mathrm{O}_{2}$ was determined to be $1.9 \times 10^{-4} \mathrm{~s}^{-1}$ (Fig. S6), similar to those reported in a previous study (An et al., 2001) that used the same brand and model of UV lamp. A photolysis rate constant of $1.0 \times 10^{-4} \mathrm{~s}^{-1}$ was determined by taking into account reactions with other reactive oxygen species such as $\mathrm{OH}$ and $\mathrm{HO}_{2}$ radicals (see Supplement Sect. 4, Table S2 and Fig. S6 for details). The $\mathrm{OH}$ concentration in the aqueous solution was estimated by two approaches (see Supplement Sect. 4 and Figs. S7 and S8 for details): (1) assuming a pseudo-steady-state of $\mathrm{OH}$ radicals, and (2) solving the stiff ordinary differential equations with no constraint on the $\mathrm{OH}$ radical concentration. The first approach resulted in an $\mathrm{OH}$ concentration of about $7.2 \times 10^{-12} \mathrm{M}$, while the second one gave a concentration of about $7.0 \times 10^{-12} \mathrm{M}$. The $\mathrm{OH}$ concentration in the aqueous solution is thus believed to be one order of magnitude higher than that in cloud water (Fig. S7), which is generally on the order of $10^{-13} \mathrm{M}$ (Ervens et al., 2013; Warneck, 2003), but is close to that in fog or wet aerosol particles (Ervens et al., 2011).

\subsection{Off-line analyses}

Aqueous-phase samples collected at different time intervals were analyzed using three off-line techniques. An ultraperformance liquid chromatograph (UPLC) with a diode array detector (DAD) was used to quantify the reactant VL and an expected product, vanillic acid (VA), in experiments A_1 to $A \_3$ and B_1 to B_3. An UPLC with electrospray ionization (ESI) coupled with a time-of-flight mass spectrometric detector (ToF-MS) was used to identify reaction products that have relatively large molecular weights, that is, mainly those from condition (B). Product identification with derivatizations prior to gas chromatography and mass spectrometry (GC-MS) was also conducted for small oxygenated products, which were mainly found under condition (A). Two 
Table 1. Summary of experimental conditions and measurements.

\begin{tabular}{|c|c|c|c|c|c|c|c|c|}
\hline \multirow{2}{*}{$\frac{\text { Exp no. }}{\text { A_1 }}$} & \multicolumn{4}{|c|}{ Condition } & \multirow{2}{*}{$\frac{\text { Off-line }^{\mathrm{e}}}{\mathrm{Y}}$} & \multirow{2}{*}{$\frac{\mathrm{AMS}^{\mathrm{f}}}{\mathrm{Y}}$} & \multirow[t]{2}{*}{ HTDMA $^{\mathrm{g}}$} & \multirow[t]{2}{*}{$\mathrm{CCNc}^{\mathrm{h}}$} \\
\hline & $\mathrm{AS}^{\mathrm{a}}$ & $\mathrm{VL}^{\mathrm{b}}$ & $\mathrm{H}_{2} \mathrm{O}_{2}^{\mathrm{c}}$ & UV on ${ }^{d}$ & & & & \\
\hline A_2 & AS & VL & $\mathrm{H}_{2} \mathrm{O}_{2}$ & UV on & $\mathrm{Y}$ & $\mathrm{Y}$ & & \\
\hline A_3 & AS & VL & $\mathrm{H}_{2} \mathrm{O}_{2}$ & UV on & Y & Y & & \\
\hline B_1 & AS & VL & - & UV on & $\mathrm{Y}$ & Y & Y & \\
\hline B_2 & AS & VL & - & UV on & $\mathrm{Y}$ & Y & Y & \\
\hline B_3 & AS & VL & - & UV on & $\mathrm{Y}$ & Y & Y & \\
\hline A_4 & AS & VL & $\mathrm{H}_{2} \mathrm{O}_{2}$ & UV on & & Y & Y & \\
\hline A_5 & AS & VL & $\mathrm{H}_{2} \mathrm{O}_{2}$ & UV on & & Y & Y & \\
\hline A_6 & AS & VL & $\mathrm{H}_{2} \mathrm{O}_{2}$ & UV on & & Y & Y & \\
\hline A_7 & AS & VL & $\mathrm{H}_{2} \mathrm{O}_{2}$ & UV on & & Y & Y & Y \\
\hline A_8 & AS & VL & $\mathrm{H}_{2} \mathrm{O}_{2}$ & UV on & & Y & Y & Y \\
\hline B_4 & AS & VL & - & UV on & & Y & Y & Y \\
\hline B_5 & AS & VL & - & UV on & & Y & Y & Y \\
\hline B_6 & AS & VL & - & UV on & & Y & Y & Y \\
\hline A_9 & - & VL & $\mathrm{H}_{2} \mathrm{O}_{2}$ & UV on & Y & & & \\
\hline B_7 & - & VL & - & UV on & Y & & & \\
\hline C_-1 & AS & - & - & UV on & & Y & Y & Y \\
\hline C_2 & AS & - & $\mathrm{H}_{2} \mathrm{O}_{2}$ & UV on & & Y & Y & Y \\
\hline C_-3 & AS & VL & - & - & & Y & & \\
\hline C_4 & AS & VL & $\mathrm{H}_{2} \mathrm{O}_{2}$ & - & & Y & & \\
\hline
\end{tabular}

${ }^{\mathrm{a} A m m o n i u m ~ s u l f a t e}(0.1 \mathrm{mM}) ;{ }^{\mathrm{b}}$ vanillin $(0.1 \mathrm{mM})$; ${ }^{\mathrm{c}}$ hydrogen peroxide $(11.8 \mathrm{mM}) ;{ }^{\mathrm{d}} \mathrm{UV}$ lamp $(254 \mathrm{~nm}) ;{ }^{\mathrm{e}}$ samples collected for off-line analyses (A_1 to A_3 and B_1 to B_3 for UPLC-DAD analysis; A_9 and B_7 for UPLC-ToF-MS analysis); ${ }^{\mathrm{f}}$ high-resolution time-of-flight aerosol mass spectrometric measurements; ${ }^{\mathrm{g}}$ hygroscopic tandem differential mobility analyzer measurements; ${ }^{h}$ : cloud condensation nuclei measurements. "-" indicates certain species (AS, VL, or $\mathrm{H}_{2} \mathrm{O}_{2}$ ) or element (UV) were not included in the experiments. "Y" indicates sample collection and on-line analyses using the specific instrument.

derivatization methods were employed. The first one uses the $\mathrm{BF}_{3} /$ butanol to convert carboxylic acids to butyl esters (Li and $\mathrm{Yu}, 2005$ ). The second one uses pentafluorophenylhydrazine (PFPH) to convert carbonyl compounds to their PFPH derivatives (Dron et al., 2008). Details of off-line analyses can be found in the Supplement Sect. 5.

\subsection{HTDMA and CCNc analyses}

During experiments A_4 to A_8 and B_1 to B_6, particles leaving the diffusion dryer were characterized by an HTDMA system (BMI, Haywood, CA, USA). Dried particles entered a differential mobility analyzer (DMA1) operating under dry conditions (relative humidity, $\mathrm{RH}<5 \%$ ) and left DMA1 with a mono-disperse particle size with mobility diameter, $D_{\text {dry }}=100 \mathrm{~nm}$. They then entered a humidifier with a controlled RH of $90 \%$ to effect hygroscopic growth. After growth, the size distribution over the mobility diameter $D_{90}$ was measured with a second DMA (DMA2) operating in scanning mode and coupled with a mixing condensation particle counter (MCPC). The hygroscopic growth factor, $\mathrm{GF}_{90}$, defined as the ratio of the humidified (at $90 \% \mathrm{RH}$ ) particle diameter to the dry particle diameter, was then obtained. Note that under condition (A) when substantial amounts of small oxygenates were formed, the dried particles may not be completely water free. Although there is uncertainty in the esti- mation without the exact knowledge of the amounts of all the small oxygenates and high electrolyte concentrations, EIM-II (Clegg et al., 1998) predicted a $<2 \%$ difference in the $D_{\text {dry }}$.

$\mathrm{GF}_{90}=\frac{D_{90}}{D_{\text {dry }}}$

In the $\mathrm{CCN}$ measurements (A_7 to A_8 and B_4 to B_6) for the cloud condensation activity, dry particles leaving the diffusion dryer passed through a TSI (Shoreview, MN) DMA and were split into two streams. One stream was directed to a TSI water-based CPC and the other to the CCN counter (CCNc, model CCN-200, DMT, Boulder, CO). The particle number concentration $\left(N_{\mathrm{CN}}\right)$ was obtained by the CPC. In the $\mathrm{CCNc}$, an effective water vapor supersaturation (ss) of $0.1 \%$ was set. Particles that had a critical supersaturation below the set value were then activated and grew into droplets. The concentration $\left(N_{\mathrm{CCN}}\right)$ and size distribution of activated droplets were detected by an optical particle counter at the bottom exit of the CCNc column.

The CCN activation of the particles was examined by plotting the CCN efficiency against the diameter $\left(D_{\mathrm{p}}\right)$ of dry particles selected by a DMA and counted by a CPC. The CCN efficiency is defined as the ratio of the concentration of the activated droplets to that of the dry particles $\left(N_{\mathrm{CCN}} / N_{\mathrm{CN}}\right)$. After making a correction for doubly charged particles, each CCN efficiency spectrum was fitted with a 
cumulative Gaussian distribution function using a non-linear least-square fitting routine. The $D_{50}$, indicating $50 \%$ of the particles at this diameter are activated, was then obtained. Since the supersaturation was fixed during the experiment, changes in $D_{50}$ would reflect changes in the CCN activity of the particles, which is related to the particle chemical composition.

\section{Results and discussion}

\subsection{AMS Organic fractions and mass spectra}

Aqueous-phase reactions under both conditions (A) and (B) were triggered by UV light. Under condition (A) when $\mathrm{H}_{2} \mathrm{O}_{2}$ was present, $\mathrm{OH}$ radicals were generated and oxidation of $\mathrm{VL}$ proceeded mainly via reactions with $\mathrm{OH}$. Under condition (B) when $\mathrm{H}_{2} \mathrm{O}_{2}$ was absent, direct photolysis of $\mathrm{VL}$ was the main reaction route (Benitez et al., 1997), although a small amount of reactive oxygen species including $\mathrm{H}_{2} \mathrm{O}_{2}$ was very likely generated (Anastasio et al., 1997). The differences between these two conditions can be clearly seen from the increases in AMS-measured particulate organic mass concentration (green line) and the ratio of organic to sulfate mass (Org $/ \mathrm{SO}_{4}^{2-}$ ) (black circles) in Fig. S3 (for experiments $A \_1$ to $A \_3$ in the upper panel and $B \_1$ to $B \_3$ in the lower panel). Shown in Fig. 1 are the 10 min running average $\mathrm{Org} / \mathrm{SO}_{4}^{2-}$ ratios for all the experiments (A_1 to $\mathrm{A} \_8$ in panel A, and B_1 to B_6 in panel B), together with the average mass fractions of organics (green) and ammonium sulfate (red). Under condition (A), the $\mathrm{Org} / \mathrm{SO}_{4}^{2-}$ ratio increased rapidly and reached 1.58 (the original $\mathrm{VL} / \mathrm{SO}_{4}^{2-}$ mass ratio of the reacting solution) in around $30 \mathrm{~min}$. The overshooting of the $\mathrm{Org} / \mathrm{SO}_{4}^{2-}$ ratio up to 1.80 was probably because addition of oxygen mass due to functionalization out-weighed the loss of VL and/or volatile products during the photochemical oxidation. Note that the usage of the default relative ionization efficiency of organics (1.4) may introduce an uncertainty of $\sim 20 \%$ and $\sim 15 \%$ in the estimation of the organic and the sulfate concentrations (Bahreini et al., 2009), respectively, which would result by error propagation in an uncertainty of $\sim 25 \%$ for the highest $\mathrm{Org} / \mathrm{SO}_{4}^{2-}$ ratio. After around $40 \mathrm{~min}$, the $\mathrm{Org} / \mathrm{SO}_{4}^{2-}$ ratio started to decrease slowly. After around 3 hours, the $\mathrm{Org} / \mathrm{SO}_{4}^{2-}$ ratio fell to around 0.1 , indicating that the organics were mostly converted to volatile products by extensive fragmentation.

Under condition (B), the $\mathrm{Org} / \mathrm{SO}_{4}^{2-}$ ratio increased steadily throughout the $3 \mathrm{~h}$ reaction period. It reached around 1.0 and the organic mass fraction was around $40 \%$ by the end of the experiments. Hence, without a high $\mathrm{OH}$ radical concentration, direct photolysis of VL by UV light with a wavelength of $254 \mathrm{~nm}$ for $3 \mathrm{~h}$ resulted in the retention of only approximately $60 \%$ (the highest $\mathrm{Org} / \mathrm{SO}_{4}^{2-}$ ratio of around 1.0 divided by original $\mathrm{VL} / \mathrm{SO}_{4}^{2-}$ ratio of 1.58 ) of the organic mass in the particle phase after reactions and drying.

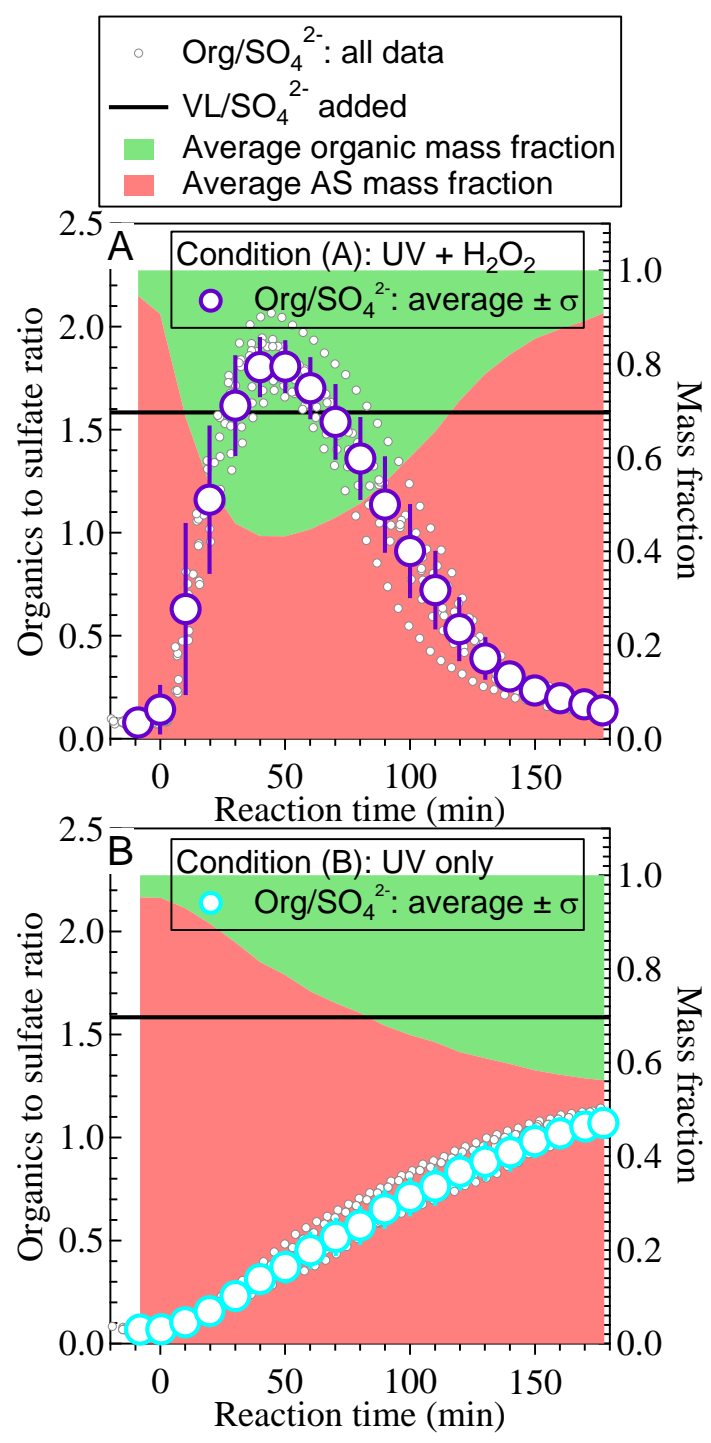

Fig. 1. Ratios of organics to sulfate, as well as mass fractions of organic and ammonium sulfate during experiments under conditions (A) and (B). Small grey symbols show data from all experiments (A_1 to A_8 or B_1 to B_6), while large color symbols show $10 \mathrm{~min}$ running averages with error bars representing standard deviations.

The rest is likely VL that has not reacted or its volatile products, both of which would evaporate during the drying process.

In the high-resolution mass spectra obtained under the W mode (Fig. 2a), ions with high $\mathrm{m} / \mathrm{z}$ values were present in the first $10 \mathrm{~min}$ of reactions under condition (A). For example, the peak of $m / z 137$ (see grey arrow in panel a) was dominated by an ion with a formula of $\mathrm{C}_{7} \mathrm{H}_{5} \mathrm{O}_{3}^{+}$. This $m / z$ value has been observed in biomass burning organic aerosols and was assigned to lignin-related ions with methoxy-phenolic structures ( $\mathrm{Li}$ et al., 2011b). Therefore, this ion is believed to be a fragment of the ring-retaining products that still possess the methoxy-phenolic structure. After $40 \mathrm{~min}$, the ions with 
high $m / z$ values became less abundant. Instead, the ions of $\mathrm{CO}^{+}\left(m / z\right.$ 28) and $\mathrm{CO}_{2}^{+}(m / z$ 44) dominated. At $120 \mathrm{~min}$, these two ions became overwhelmingly dominant in the mass spectrum. In contrast, the ions with high $m / z$ values were still of relatively high fractions under condition (B) throughout the $3 \mathrm{~h}$ experiment (Fig. 2b). The peak at $\mathrm{m} / z 137$ remained observable even at $120 \mathrm{~min}$.

The differences in the evolution of mass spectral features under these two conditions indicate that the retainable products observed were substantially different within the experimental timescale of $3 \mathrm{~h}$. The disappearance of highmolecular-weight ions and emergence of ions representing small oxygenates (e.g., $\mathrm{CO}^{+}$and $\mathrm{CO}_{2}^{+}$) under condition (A) suggested that fragmentation might dominate over functionalization. Fragmentation was very likely via ring-opening pathways, leading to the formation of carboxylic acids which generated high intensity of $m / z 44\left(\mathrm{CO}_{2}^{+}\right)$in AMS mass spectra. Under condition (B), on the other hand, the preservation of the methoxy-phenolic structure was evidenced by the presence of $m / z \quad 137\left(\mathrm{C}_{7} \mathrm{H}_{5} \mathrm{O}_{3}^{+}\right)$. Reactions might have proceeded mainly via functionalization with the ring retained. Note that even under condition (B), the intensities of highmolecular-weight ions decreased but those of $\mathrm{m} / z 18$ and $m / z 44$ increased too, which suggested that fragmentation has occurred, albeit at a less extent than that under condition (A).

\subsection{Degree of oxygenation}

The oxygen-to-carbon $(\mathrm{O}: \mathrm{C})$ and hydrogen-to-carbon $(\mathrm{H}: \mathrm{C})$ ratios are shown in Fig. 3 for both conditions. The $\mathrm{O}: \mathrm{C}$ ratio under condition (A) increased for the first $80 \mathrm{~min}$ before it decreased. This appears to contradict the extensively oxidative environment during the experiments. However, since the AMS-measured organic products were only those that remained in the particle phase, some of the more oxygenated products, for example, formic acid $(\mathrm{O}: \mathrm{C}=2)$ from fragmentation reactions, as a very oxygenated and volatile product of the oxidation, may have escaped from the particle phase and evaded detection by the AMS. A similar fragmentation-induced formation of "less oxygenated" SOA was also observed with a decrease in $\mathrm{O}: \mathrm{C}$ during the gasphase photochemical oxidation of biomass burning organic aerosols (Heringa et al., 2011). On the other hand, mineralization to $\mathrm{CO}_{2}$ as the end product may also have caused a substantial decrease in the $\mathrm{O}: \mathrm{C}$ of the particulate organics measured. Although not measured, $\mathrm{CO}_{2}$ very likely formed during the experiment because the $\mathrm{O}: \mathrm{C}$ at $80 \mathrm{~min}$ had already increased to 1.5 , approaching the upper limit for the commonly observed particulate organic species (e.g., 2.0 for oxalic acid). The $\mathrm{O}: \mathrm{C}$ ratio under condition (B) increased, first rapidly and then slowly during the $3 \mathrm{~h}$ of reactions. This indicates that oxidation under condition (B) was not as complete as that under condition (A), because $\mathrm{O}: \mathrm{C}$ under condition (B) was only $\sim 1.0$ at the end of the experiments. There- fore, the organic products that retained in the particle phase at the time of highest $\mathrm{O}: \mathrm{C}$ ratio under condition $(\mathrm{B})(\sim 3 \mathrm{~h})$ are believed to be less oxygenated than those under condition (A) ( $\sim 80 \mathrm{~min})$. The $\mathrm{H}: \mathrm{C}$ ratio decreased slightly under both conditions at the beginning of the experiments. While the $\mathrm{H}$ : C ratio was relatively stable throughout the rest of the experiment under condition (B), it increased slightly under condition (A) near the end of the experiment.

\subsection{Kinetics of vanillin decay}

The reactant VL and an expected product vanillic acid (VA) were quantified using standard compounds and offline UPLC-DAD (see Supplement Sect. 5.1, Figs. S9 and $\mathrm{S} 10)$. Figure $4 \mathrm{a}$ and $\mathrm{b}$ show the ratios of these two compounds (green solid circles and red solid triangles) to sulfate (assumed constant at $0.1 \mathrm{mM}$ ) during experiments under conditions (A) and (B), respectively. Under condition (A), $\mathrm{VL} / \mathrm{SO}_{4}^{2-}$ decreased rapidly during the first 30 min after the UV lamp was switched on, coinciding with the rapid increase in Org $/ \mathrm{SO}_{4}^{2-}$ revealed by the AMS measurements. $\mathrm{VA} / \mathrm{SO}_{4}^{2-}$ increased slightly in the first $10 \mathrm{~min}$ but decreased to almost zero after $30 \mathrm{~min}$, suggesting that VA was only an important product at the beginning of the experiment under condition (A) but was almost completely converted to other products after $30 \mathrm{~min}$ of photochemical oxidation. Under condition (B), $\mathrm{VL} / \mathrm{SO}_{4}^{2-}$ decreased slowly, corresponding to a similarly slow increase in $\mathrm{Org} / \mathrm{SO}_{4}^{2-}$ observed in the AMS measurements. VA remained as a minor product during the reactions under condition (B), suggesting some other products (see below) were formed during the consumption of VL.

Figure $4 \mathrm{c}$ and d show the decay rate $\left(k_{\mathrm{obs}} \mathrm{s}^{-1}\right)$ of VL under conditions (A) and (B), respectively. The decay rate under condition (A) was one order of magnitude larger than that under condition (B). Using the estimated $\mathrm{OH}$ steady-state concentration $\left(7.0 \times 10^{-12} \mathrm{M}\right)$, a bimolecular reaction rate constant of $\mathrm{VL}$ and $\mathrm{OH}$ under condition (A) was estimated to be $4 \times 10^{8} \mathrm{M}^{-1} \mathrm{~s}^{-1}$ (see Supplement Sect. 4 and Fig. S8 for details). For condition (B), reactions were likely triggered by activation of the aromatic VL by UV light, followed by production of a smaller amount of $\mathrm{H}_{2} \mathrm{O}_{2}$ (Anastasio et al., 1997) than under condition (A), which in turn generated a much lower concentration of $\mathrm{OH}$ radicals than under condition (A). In the initial stage of the experiment (i.e., the first $60 \mathrm{~min}$ ), the decay rate was determined to be $2.3 \times 10^{-4} \mathrm{~s}^{-1}$. This decay rate is close to that $\left(3.6 \times 10^{-4} \mathrm{~s}^{-1}\right)$ in Benitez et al. (1997), although polychromatic light (strongest line at $366 \mathrm{~nm}$ ) was used in that study.

\subsection{Other reaction products}

Mass spectra of some of the products identified by UPLCESI-ToF-MS and GC-MS are shown in Figs. 5 and 6, respectively. Extractive ion chromatograms from UPLC-ESI-ToFMS are shown in Fig. S11. All mass spectra are shown in the 


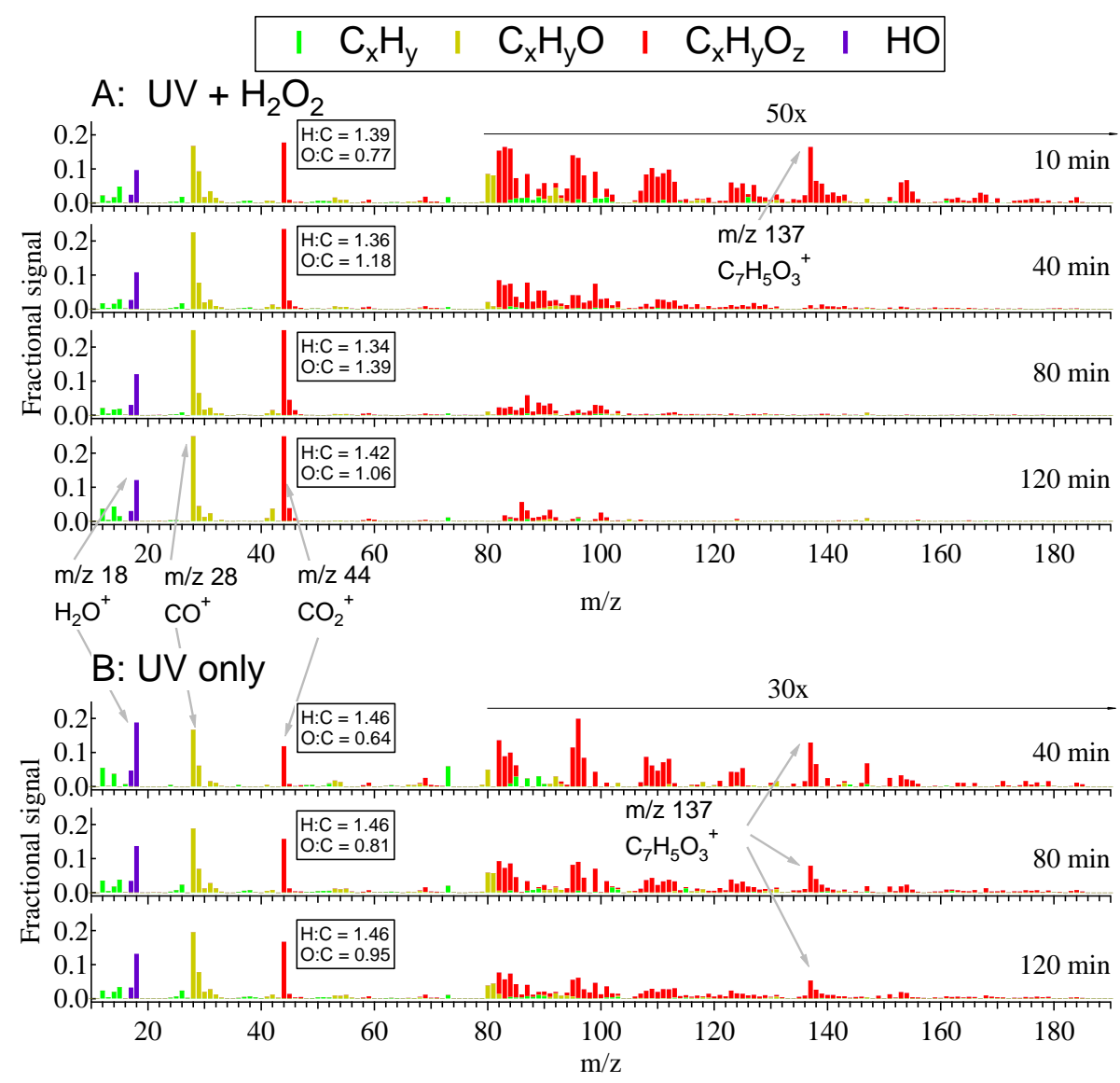

Fig. 2. Mass spectra at different reaction times under conditions (A) and (B), from experiments A_2 and B_2, respectively. The H : C and $\mathrm{O}: \mathrm{C}$ ratios are also shown for each mass spectrum. Sticks with different colors indicate different ion "families": $\mathrm{C}_{\mathrm{x}} \mathrm{H}_{\mathrm{y}}$ being ions with only $\mathrm{C}$ and $\mathrm{H}, \mathrm{C}_{\mathrm{x}} \mathrm{H}_{\mathrm{y}} \mathrm{O}$ being ions with $\mathrm{C}, \mathrm{H}$ and only one $\mathrm{O}$ atom, $\mathrm{C}_{\mathrm{x}} \mathrm{H}_{\mathrm{y}} \mathrm{O}_{\mathrm{z}}$ being ions with $\mathrm{C}, \mathrm{H}$ and more than one $\mathrm{O}$ atoms, and $\mathrm{HO}$ being ions with only $\mathrm{H}$ and $\mathrm{O}$.

Supplement Figs. S12 (for UPLC-ESI-ToF-MS) and S13 (for GC-MS).

Using the UPLC-ESI-ToF-MS, no major products were detected in samples under condition (A), probably due to poor separation in LC and inefficient ionization by ESI for those products formed under condition (A). As discussed earlier in Sect. 3.1, ring-opening and highly oxygenated products with low molecular weights (e.g., small carboxylic acids or aldehydes) are expected to form under extensive photochemical oxidation under condition (A). Indeed, it is not efficient to separate small oxygenates in a reverse-phase LC column (Buszewski and Noga, 2012) and to ionize small oxygenates that are too hydrophilic by ESI (Cech et al., 2001). Multiple products were observed by the UPLC-ToF-MS in samples under condition (B), and they are listed in Table S3. A number of monomeric products with retention times of around $10 \mathrm{~min}$ (Fig. S11), including B168_a (Fig. 5a), B168_b, and B168_c with a molecular formula of $\mathrm{C}_{8} \mathrm{H}_{8} \mathrm{O}_{4}$, as well as B184_a and B184_b with a molecular formula of $\mathrm{C}_{8} \mathrm{H}_{8} \mathrm{O}_{5}$, were observed after $40 \mathrm{~min}$ of reaction under condition (B). Among them, B168_b is believed to be
VA as detected by the UPLC-DAD method, based on its fragmentation pattern which showed a $\mathrm{CO}_{2}$ loss (Li et al., 2011a). Similarly, the observed product B184_a (Fig. 5b) is also believed to bear a carboxylic group based on its fragmentation pattern which showed a $\mathrm{CO}_{2}$ loss (Table S3). Other isomers might be di- or tri-hydroxylated products with one or two more hydroxyl groups (in additional to the original one) at the three available positions on the aromatic ring.

Seven products with longer retention times $(32-35 \mathrm{~min})$ were observed after $120 \mathrm{~min}$ of reaction under condition (B), as shown in Table S3 and Fig. S11. The mass spectra of these products are shown in Fig. S12. The oligomeric product B302_a (Fig. 5c) is believed to be a dimer formed via radical-radical polymerization, similar to reactions of other phenols (Sun et al., 2010). Mass spectra of other observed oligomers contain less information on fragmentation for further structural elucidation thus the structures of those products are not proposed and their formation mechanisms remain unknown. Nevertheless, those products have similarly high conjugation as B302_a because their double-bond equivalency is higher than (or at least close to) that of B302_a 

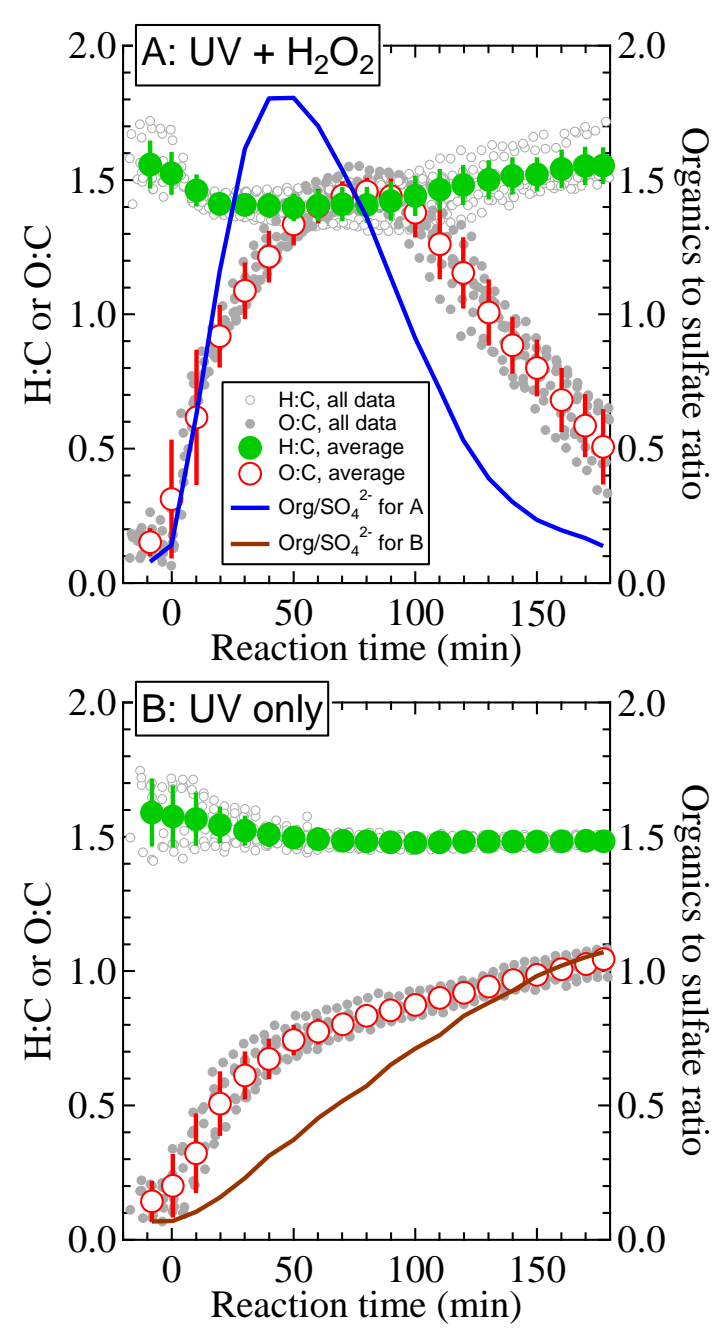

Fig. 3. $\mathrm{H}: \mathrm{C}$ and $\mathrm{O}: \mathrm{C}$ ratios as a function of time under conditions (A) and (B). Also shown are the 10 min running average ratios of organics to sulfate (solid lines) under these two conditions.

(Table S3). Additionally, a yellowish color was observed for solutions after experiments under condition (B) while it was not observed under condition (A). This observation suggests that the highly conjugated products as detected by the UPLCToF-MS might be responsible for the light absorption of the solution.

From samples under condition (A), four small carboxylic acids including glyoxylic acid, oxalic acid, malonic acid, and pyruvic acid, as well as two aldehydes including formaldehyde and glyoxal, were identified using the two aforementioned derivatization methods prior to GC-MS analyses (Fig. S13). Figure 6 shows the standard and sample mass spectra of derivatized oxalic acid (Fig. 6a), glyoxylic acid (Fig. 6b), and glyoxal (Fig. 6c). These small oxygenates were detected in samples at $80-120 \mathrm{~min}$ after the start of the reactions. The formation of these small oxygenates confirms that with intensive photochemical oxida- tion under condition (A), vanillin molecules were extensively fragmented (ring-opening) to yield smaller and more functionalized products.

From the above product information, it can be concluded that the reaction pathways under conditions (A) and (B) are very different. Under condition (A), photochemical oxidation may proceed via ring-opening pathways that lead mainly to small oxygenates, resulting in a very high degree of oxygenation as indicated by the $\mathrm{O}: \mathrm{C}$ ratios seen in the AMS results (Fig. 3a). Under condition (B), reactions seemed to occur mostly via ring-retaining pathways, resulting in the addition of one or more hydroxyl groups. Dimerization of vanillin also occurred under this condition. These two reaction pathways under condition (B) resulted in a mild increase in the $\mathrm{O}: \mathrm{C}$ ratios, consistent with the AMS measurements (Fig. 3b). However, all the products tentatively identified by the UPLC-ToF-MS have O : $\mathrm{C}$ ratios far below 0.9 at $120 \mathrm{~min}$, the $\mathrm{O}: \mathrm{C}$ ratio obtained from AMS measurements. The products observed by the UPLC-ToF-MS represented those in the solution, and some of them (with low $\mathrm{O}: \mathrm{C}$ ratios) might not retain in the particles. Those that retained (but not identified using the current techniques) might have higher $\mathrm{O}: \mathrm{C}$ ratios than those observed by the UPLC-ToFMS method. It is possible that some small oxygenates with high $\mathrm{O}: \mathrm{C}$ ratios were also produced under condition (B), albeit to a lesser extent, as the UPLC-DAD measurements indicated (see Supplement Sect. 5.1).

\subsection{Hygroscopicity and CCN activity}

The mixed inorganic (AS) and organic particles were characterized by HTDMA and CCNc analyses during the reactions under both conditions. AS had a measured (Fig. 7a and c, before reactions) $\mathrm{GF}_{90}$ of 1.68 for a dry size of $100 \mathrm{~nm}$, close to that in the literature (Duplissy et al., 2009). A critical activation diameter of $\sim 115 \mathrm{~nm}$ for AS at $\mathrm{ss}=0.1 \%$ was measured (Fig. $7 \mathrm{~b}$ and d, before reactions), slightly smaller than the $129 \mathrm{~nm}$ measured at $0.09 \%$ ss (Roberts and Nenes, 2005). Under condition (A), the $\mathrm{GF}_{90}$ decreased rapidly as the organic volume fraction increased. Interestingly, the lowest GF did not correspond to the highest organic volume fraction (Fig. 7a). Instead, the GF started to increase slightly as the organic volume fraction increased from around 0.55 to 0.60 (AS volume fraction from 0.45 to 0.40 ), corresponding to the reaction times of around $30 \mathrm{~min}$ and $40 \mathrm{~min}$, respectively. This indicates that at $40 \mathrm{~min}$, the organic products were more hygroscopic than those at $30 \mathrm{~min}$, assuming the contribution from the inorganic component (AS) was constant. This is in agreement with the observation that the degree of oxygenation, as indicated by the $\mathrm{O}: \mathrm{C}$ ratio, increased rapidly in the first $40 \mathrm{~min}$ of the experiments under condition (A). After $40 \mathrm{~min}$, the organic volume fraction started to decrease and the $\mathrm{GF}_{90}$ further increased. After $80 \mathrm{~min}$, the GF continued to increase although the $\mathrm{O}: \mathrm{C}$ ratio of organics began to decrease. This is because the organic volume 

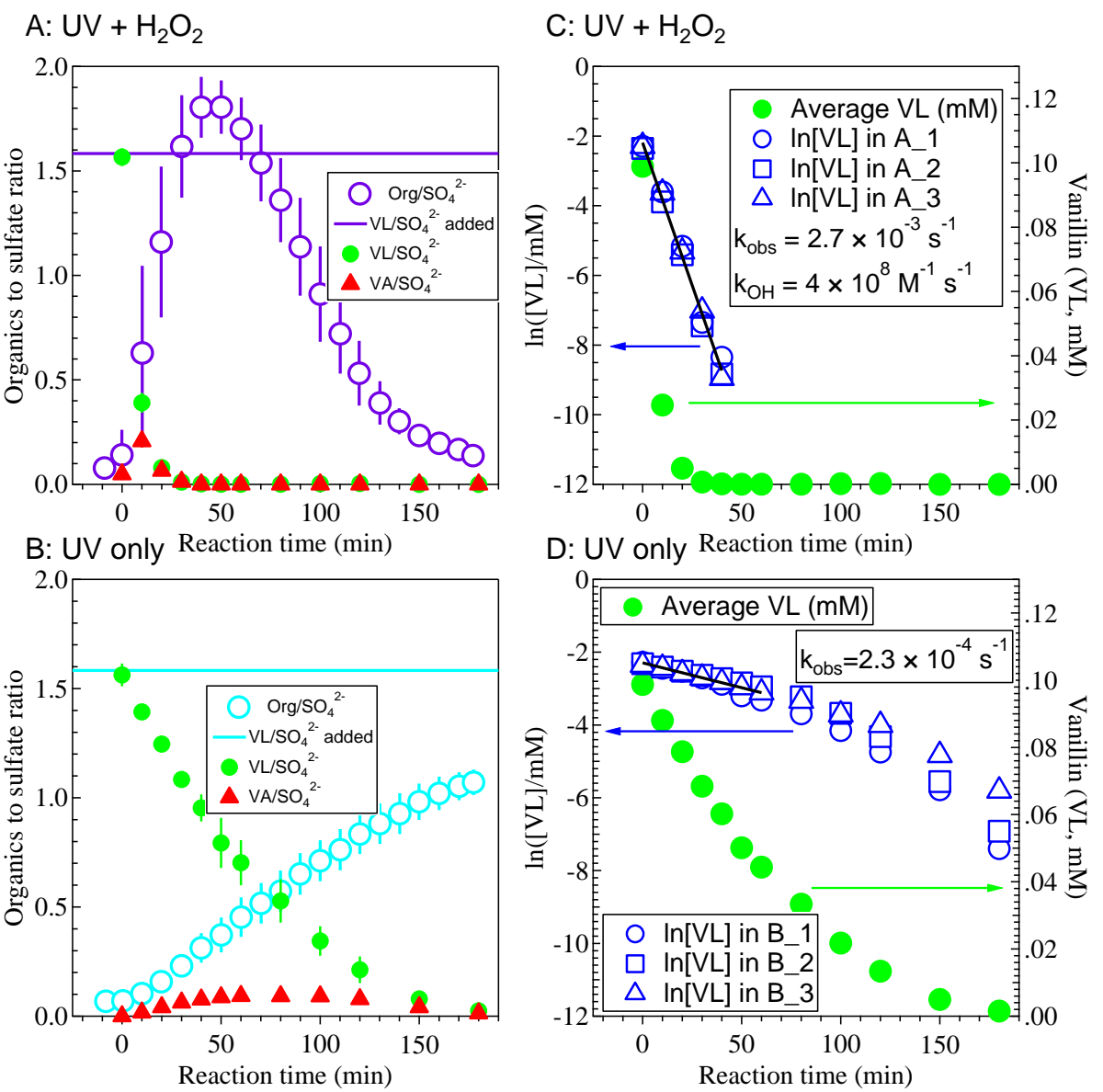

Fig. 4. The ratio of vanillin (VL) to sulfate and the ratio of vanillic acid (VA) to sulfate (panels a and b), their absolute concentrations in the aqueous solution and the natural log of their absolute concentrations (panels $\mathbf{c}$ and $\mathbf{d}$ ) under the two reaction conditions. Decay rate constants $\left(k_{\mathrm{obs}}\right)$ were determined at the first 50-60 min of the reactions. See main text for the discussion on the rate constant for the bimolecular reaction between $\mathrm{VL}$ and $\mathrm{OH}\left(k_{\mathrm{OH}}\right)$ for condition $(\mathrm{A})$ in panel (c).

fraction had decreased substantially and the $\mathrm{GF}_{90}$ was overwhelmingly dominated by the inorganic AS again. The $D_{50}$ showed a reverse trend in Fig. 7b. Under condition (B), however, the GF decreased continuously, with the rate of decrease higher at the beginning than at the end of the experiments (Fig. 7c). Correspondingly, the $D_{50}$ increased throughout the experiment under condition (B) (Fig. 7d).

To quantitatively understand the effects of organic products from these two conditions on particle hygroscopicity, the hygroscopic growth factors of the organic species at different reaction time intervals were estimated using the ZdanovskiiStokes-Robinson mixing rule. The details of hygroscopic growth factor estimation are shown in Sect. 6 of the Supplement. The hygroscopic growth factors of organic products under the two conditions as a function of the $\mathrm{O}: \mathrm{C}$ ratio are shown in Fig. 8. Only data points with organic mass fraction $>30 \%$ (volume fraction $>\sim 35 \%$ ) were included in this plot to avoid overwhelmingly dominant contribution by AS. Also shown in Fig. 8 is the fitted line from the literature (Massoli et al., 2010). A linear dependence of $\mathrm{GF}_{\text {org }}$ on the $\mathrm{O}: \mathrm{C}$ ra- tio was observed in our experiments under both conditions. But the slopes and the intercepts are quite different from those in Massoli et al. (2010). Firstly, for the $\mathrm{OH}$ oxidation experiments under condition (A), the slope is much smaller than that in Massoli et al. (2010). This may be because the range of $\mathrm{O}: \mathrm{C}$ values from our experiments in condition (A) is much higher (generally $>0.5$ for data points with organic mass fraction $>30 \%$ ) than those from chamber or field studies as in Massoli et al. (2010). The data points in Massoli et al. (2010) also started to level off with $\mathrm{O}: \mathrm{C}>0.8$. Indeed, if the $\mathrm{O}: \mathrm{C}$ ratio keeps increasing up to 2.0 (e.g., for oxalic acid), neither of these two linear relationships would hold because the $\mathrm{GF}_{90}$ values of smaller carboxylic acids such as oxalic acid are generally less than 1.5 (Peng et al., 2001). For experiments conducted under condition (B), the $\mathrm{GF}_{\text {org }}$ was substantially lower than in the Massoli et al. (2010) and under condition (A) in our study. This indicates that the relationship between GF and $\mathrm{O}: \mathrm{C}$ ratio of those highly conjugated organic compounds such as those formed from condition (B) 

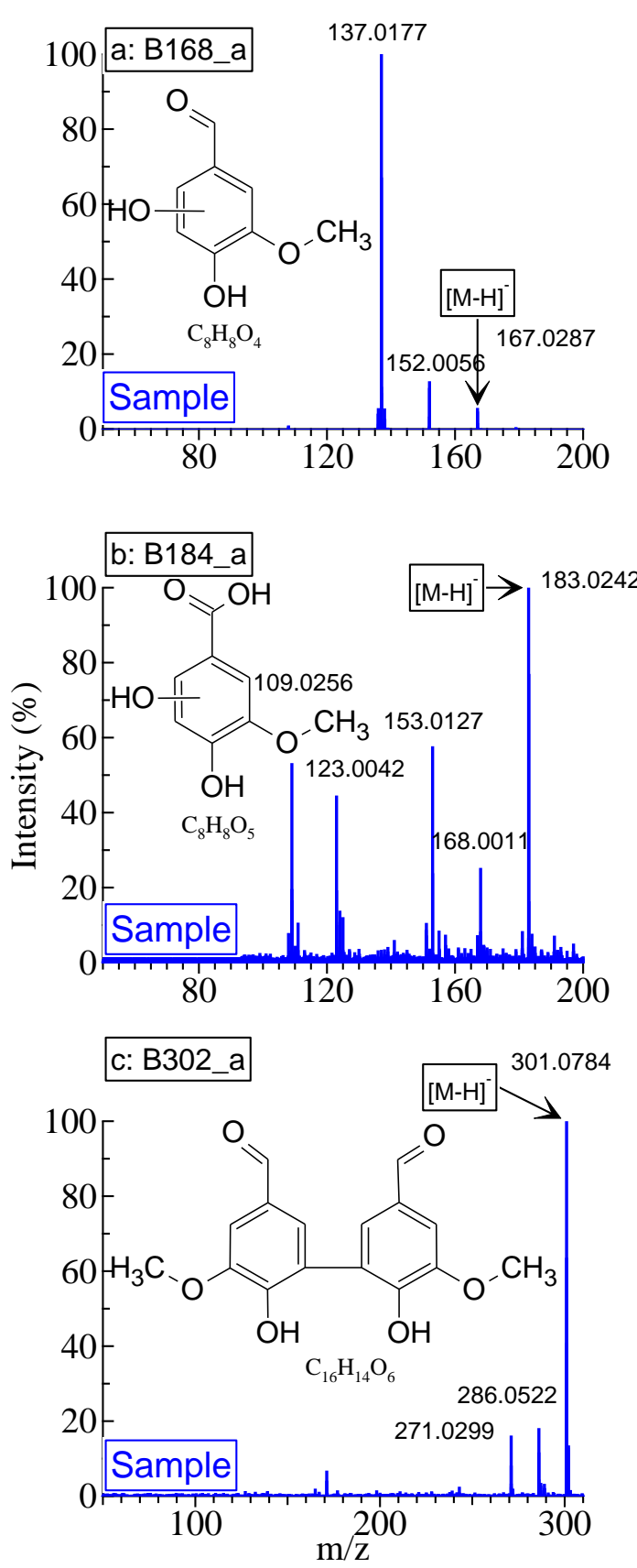

Fig. 5. Mass spectra of some of the products identified by UPLCESI-ToF-MS under condition (B). Mass spectra of other products identified by UPLC-ESI-ToF-MS can be found in Fig. S12 in the Supplement.

and generally present in BBOA may be substantially different from that for chamber SOA.

\subsection{Aqueous-phase processing}

To relate the current experiments to ambient aqueous droplets, we now compare the timescales of these experiments to the atmospheric life times of clouds and VL.

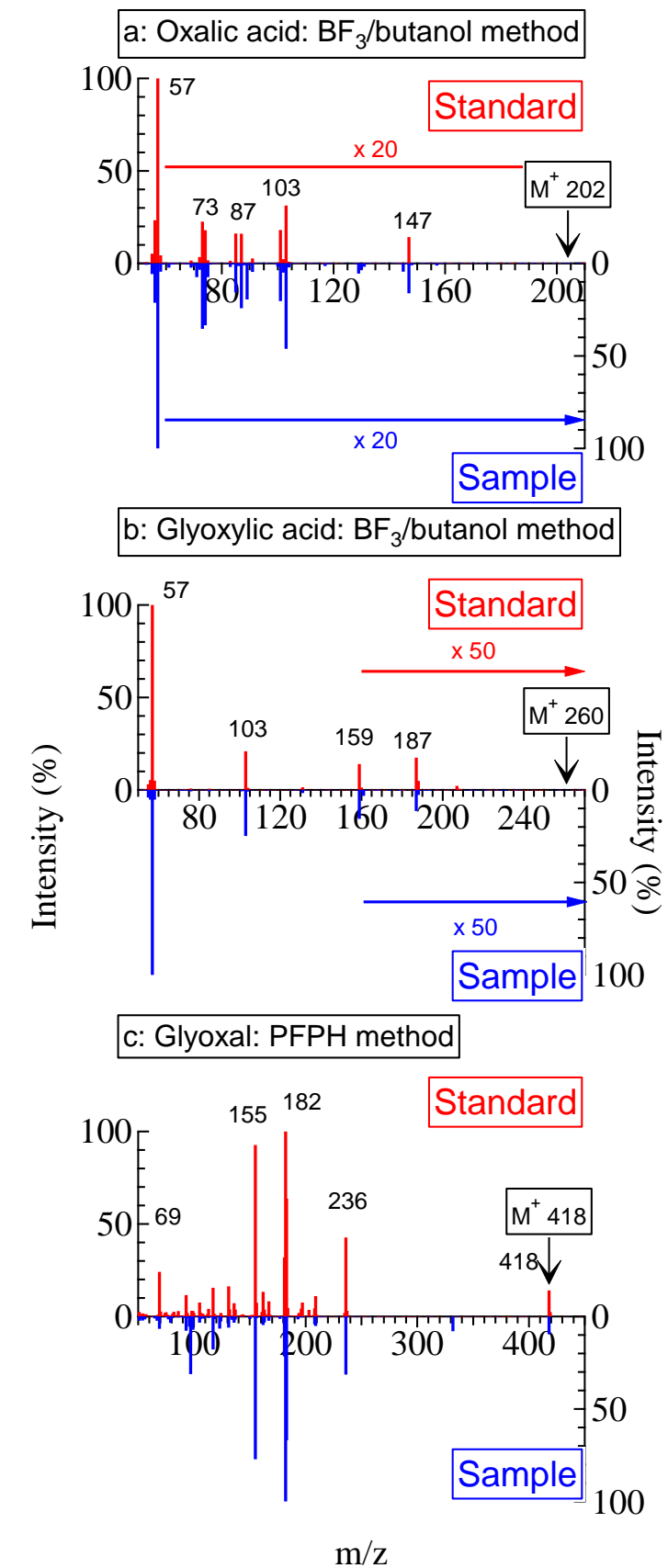

Fig. 6. Mass spectra of derivatized standard compounds (shown in red) and mass spectra of derivatized samples (shown in blue) that contained small oxygenates obtained by GC-MS. Mass spectra of other low-molecular-weight products can be found in Fig. S13 in the Supplement.

The $\mathrm{OH}$ concentration in clouds is usually on the order of $10^{-13} \mathrm{M}$ (Ervens et al., 2011; Warneck, 2003), while the $\mathrm{OH}$ concentration in our experiments was one order of magnitude higher. With a concentration of $1.84 \times 10^{-13} \mathrm{M}$ (Warneck, 2003), the timescale equivalent to our experimental time ( $3 \mathrm{~h}$ ) would be $\sim 110 \mathrm{~h}$ for a similar $\mathrm{OH}$ exposure under ambient 


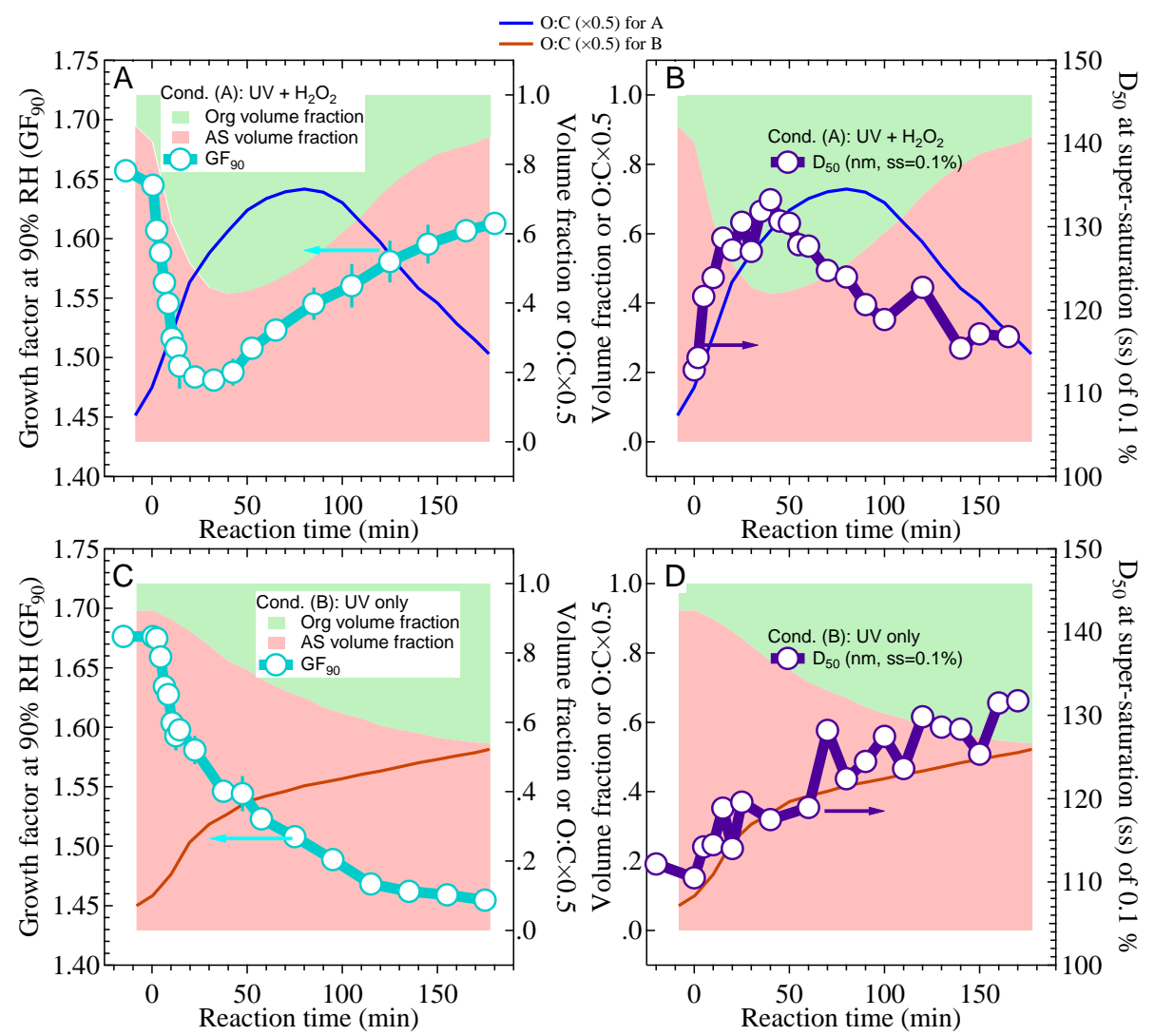

Fig. 7. HTDMA measured growth factor at $90 \% \mathrm{RH}\left(\mathrm{GF}_{90}\right)$ (panels a and c) and CCNc-measured $D_{50}$ at super-saturation (ss) of $0.1 \%$ (panels $\mathbf{b}$ and $\mathbf{d}$ ) under condition (A) (panels $\mathbf{a}$ and $\mathbf{b}$ ) and condition (B) (panels $\mathbf{c}$ and $\mathbf{d}$ ). Also shown are volume fractions of organics and ammonium sulfate, as well as $\mathrm{O}: \mathrm{C}$ ratios.

conditions. Given a cloud condensation-evaporation cycle of $0.5-3 \mathrm{~h}$ and $\sim 10$ cycles for most cloud water nuclei (Warneck, 2000), our experimental timescale for condition (A) was a few times that of the typical cloud life time. Therefore, the first 40-60 min of the experiments under condition (A) would be more relevant to ambient clouds. Oxidation in cloud is effective when biomass burning aerosols are activated to form cloud droplets, where semi-volatile methoxyphenolic compounds can be dissolved into the aqueous phase and a reasonably high concentration of $\mathrm{OH}$ can be accommodated by the droplets. Between the cloud formation cycles, water evaporates and only aerosol particles remain (together with oxidation products from the previous cloud cycle). In that case, oxidation reactions in the gas phase may be more important than in the particle phase since vanillin exists preferably in the gas phase.

For condition (B), on the other hand, oxidation reaction is not affected by the availability of $\mathrm{OH}$ from direct photolysis of $\mathrm{H}_{2} \mathrm{O}_{2}$. However, it is very likely that trace amounts of $\mathrm{H}_{2} \mathrm{O}_{2}$ would be generated during the direct photolysis of $\mathrm{VL}$, as is the case during the direct photolysis of other phenolic compounds (Anastasio et al., 1997). This small amount of $\mathrm{H}_{2} \mathrm{O}_{2}$ can also form $\mathrm{OH}$ radicals, albeit to a much lower concentration than under condition (A). The measured decay rate of $2.3 \times 10^{-4} \mathrm{~s}^{-1}$ is close to the loss rates of common water-soluble organic compounds due to aqueous-phase processes under ambient conditions (Ervens et al., 2013). This decay rate is at least comparable to the gasphase loss rate $\left(1 \times 10^{-4} \mathrm{~s}^{-1}\right)$ for VL, assuming a gas-phase oxidation rate constant of $10 \times 10^{-11} \mathrm{~cm}^{3}$ molecules ${ }^{-1} \mathrm{~s}^{-1}$ (Coeur-Tourneur et al., 2010) and a gas-phase OH concentration of $1 \times 10^{6}$ molecules $\mathrm{cm}^{-3}$ (Ervens et al., 2013). Note that this decay rate was measured with a UV lamp of $254 \mathrm{~nm}$, lower than wavelength with significant actinic flux in the troposphere $(>290 \mathrm{~nm})$. A simple calculation shows that with the absorption cross section of VL estimated from its molar absorption coefficient and an assumed quantum yield of 0.28 (resulting in the measured decay rate at $254 \mathrm{~nm}$ ), the photolysis rate in the wavelength range of tropospheric importance $(295-425 \mathrm{~nm})$ is $7.06 \times 10^{-4} \mathrm{~s}^{-1}$. The details of the calculation are provided in Sect. 7 in the Supplement. Therefore, even without $\mathrm{H}_{2} \mathrm{O}_{2}$ in the aqueous phase, the loss of methoxy-phenolic compounds like VL through the aqueousphase process (with UV light) can be as important as that through gas-phase oxidation. 


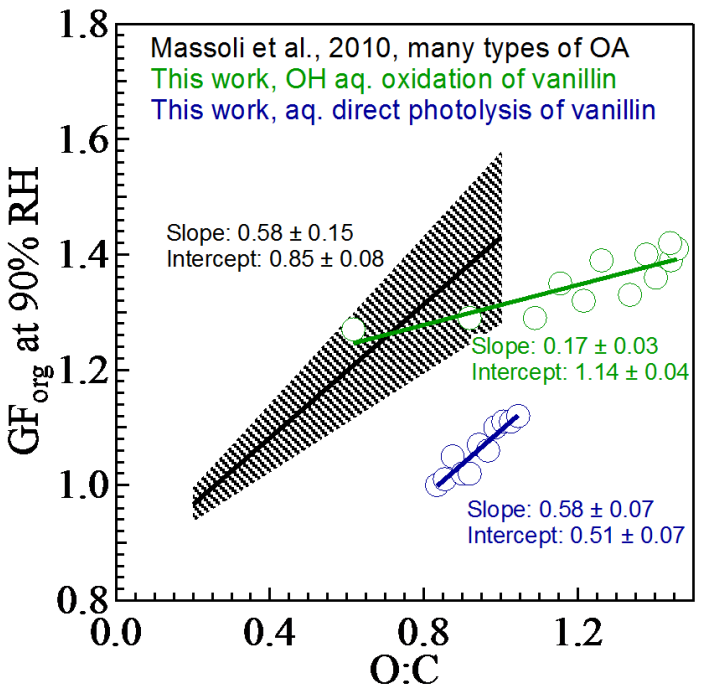

Fig. 8. Organic growth factor at $90 \% \mathrm{RH}\left(\mathrm{GF}_{\text {org }}\right)$ retrieved (see Supplement Sect. 6) from measured $\mathrm{GF}_{90}$ as a function of $\mathrm{O}: \mathrm{C}$ under condition (A) (green circles) and condition (B) (blue circles). Also shown is the dependence of $\mathrm{GF}_{\text {org }}$ at $90 \% \mathrm{RH}$ from Massoli et al. (2010) (black line and shaded area, which represents the uncertainty of fitting).

\section{Atmospheric implications}

The current work demonstrates that both (A) photochemical oxidation and (B) direct photolysis in aqueous phase can convert the intermediately volatile and slightly watersoluble vanillin into less volatile products. Unlike the precursor vanillin, some of these products can remain after the drying process and be detected as particulate organics. The products from photochemical oxidation and direct photolysis are different. Significant changes in the hygroscopicity and $\mathrm{CCN}$ activity of the particles were observed in our experiments using AS and VL as initial components. The effects of organic products on aerosol hygroscopicity under the two conditions investigated are different, in line with their different structural features. Two interesting phenomena were observed. First, under condition (A), the degree of oxygenation first increased and then decreased. Second, a yellowish coloration of the reacting mixtures and high-molecularweight products was observed mainly under condition (B). The first phenomenon suggests that aqueous-phase oxidation as under condition (A) may also have a competition between functionalization and fragmentation (Lee et al., 2012). The second phenomenon suggests that $\mathrm{OH}$ oxidation under condition (A) may lead to extensive carbon backbone breakage, while direct photolysis under condition (B) may induce radical-radical polymerization (Sun et al., 2010). Hydroxylated products and dimers (e.g., B302_a) are likely responsible for the yellowish color observed under condition (B). This observation suggests that direct photolysis of methoxy-phenolic compounds could contribute to the light- absorbing "brown carbon" observed in ambient aerosol samples (Andreae and Gelencsér, 2006), although differences between actinic radiation in typical tropospheric environments (> $290 \mathrm{~nm}$ ) and the short UV wavelength $(254 \mathrm{~nm})$ used in the experiments need to be considered. During one of the trial experiments, the same yellowish color was also observed under condition (A) at the same $\mathrm{H}_{2} \mathrm{O}_{2}$ concentration $(11.8 \mathrm{mM})$ but a 10 times higher VL concentration $(1 \mathrm{mM})$ than in all other experiments. The formation of the yellowish color may thus be dependent on the concentration ratio between $\mathrm{VL}$ and $\mathrm{OH}$ radicals. If an excess amount of VL is available, hydroxylated products and dimers with a yellowish color can still be formed under condition (A).

Well known as a source of POA, biomass burning also contributes to SOA formation by producing a large amount of slightly volatile and partially oxygenated species. Among many types of organics that are emitted from biomass burning, the methoxy-phenolic compounds of various levels of volatility deserve more attention regarding their contribution to SOA formation. It has been shown that they can be oxidized in gas phase to produce less volatile products, forming SOA (Cubison et al., 2011; Grieshop et al., 2009; Yee et al., 2013; Liu et al., 2012). Early studies using phenols as model compounds have also shown the potential role of this broad class of partially oxygenated compounds in SOA formation through aqueous-phase oxidation (Sun et al., 2010; Chang and Thompson, 2010). This study further demonstrates that the potential contribution of aqueous-phase oxidation, either photochemical oxidation or direct photolysis, to SOA formation is quite high. Once formed and mixed with other species such as inorganic salts in the particle phase, the SOA from biomass burning can strongly affect the physical properties, such as hygroscopicity and CCN activity, of atmospheric aerosol particles.

It should be noted that the current study only used a single model compound of methoxy phenols with a relatively high concentration $(0.1 \mathrm{mM})$ in aqueous phase to demonstrate the reactivity. Other methoxy phenols may vary in (i) the number of methoxy groups (e.g., p-hydroxyl, guaiacyl, and syringyl have 0,1 , and 2 methoxy groups, respectively), (ii) the number of carbon left in the propyl chain (for instance, VL only has one carbon left), and (iii) the type and position of functional groups in the propyl chain $(\mathrm{OH}, \mathrm{C}=\mathrm{O}$, or $\mathrm{COOH}$ in $\alpha, \beta$, or $\gamma$ position). These methoxy phenols may vary significantly in both saturation vapor pressure and water solubility. Although their reactivity is expected to be similar to that of VL because they share similar aromatic and partially oxygenated characteristics, their actual contribution to SOA during aqueous-phase processing warrants further investigation. On the other hand, $\mathrm{pH}$ in the aqueous droplets will have an effect on the aqueous-phase reactions (Ervens et al., 2011). Commonly found acidic aqueous phase in the atmosphere may not affect the production of $\mathrm{OH}$ radical from $\mathrm{H}_{2} \mathrm{O}_{2}$ photolysis as shown in Fig. S6, where ammonium bisulfate was used as the medium for $\mathrm{H}_{2} \mathrm{O}_{2} \mathrm{UV}$ photolysis 
at $254 \mathrm{~nm}$, with negligible difference as compared to when AS solution was used as the medium. But the acidic environment may promote hydration of some carbonyl compounds, thus alter the kinetics and even branching ratios of aqueousphase reactions. In the current study, the $\mathrm{pH}$ of the aqueous solution was not controlled, and a $\mathrm{pH}$ value was approximately 6 with $0.1 \mathrm{mM}$ of AS. Further investigation is needed to ascertain the role of acidity in the aqueous-phase reactions of methoxy-phenolic compounds. Moreover, the $\mathrm{OH}$ radical concentration used was also one order of magnitude higher than typical ambient concentrations. Nevertheless, the current work highlights the importance of SOA formation and its subsequent effects on aerosol particles from the aqueousphase processing of methoxy-phenolic compounds generated by biomass burning.

\section{Supplementary material related to this article is available online at http://www.atmos-chem-phys.net/14/ 2871/2014/acp-14-2871-2014-supplement.pdf.}

Acknowledgements. This work was supported by the Research Grants Council of the Hong Kong Special Administrative Region, China (project no. 600112 and 600413). The authors are very grateful to W. H. Fan, L. M. Yang, and L. E. Yu of the National University of Singapore for performing the UPLC-ToF-MS analyses.

Edited by: S. A. Nizkorodov

\section{References}

Allen, A. O., Hochanadel, C. J., Ghormley, J. A., and Davis, T. W.: Decomposition of water and aqueous solutions under mixed fast neutron and gamma-radiation, J. Phys. Chem., 56, 575-586, 1952.

An, Y. J., Jeong, S. W., and Carraway, E. R.: Micellar effect on the photolysis of hydrogen peroxide, Water Res., 35, 3276-3279, 2001.

Anastasio, C., Faust, B. C., and Rao, C. J.: Aromatic carbonyl compounds as aqueous-phase photochemical sources of hydrogen peroxide in acidic sulfate aerosols, fogs, and clouds .1. Non-phenolic methoxybenzaldehydes and methoxyacetophenones with reductants (phenols), Environ. Sci. Technol., 31, 218232, 1997.

Andreae, M. O. and Gelencsér, A.: Black carbon or brown carbon? The nature of light-absorbing carbonaceous aerosols, Atmos. Chem. Phys., 6, 3131-3148, doi:10.5194/acp-6-3131-2006, 2006.

Bahreini, R., Ervens, B., Middlebrook, A. M., Warneke, C., de Gouw, J. A., DeCarlo, P. F., Jimenez, J. L., Brock, C. A., Neuman, J. A., Ryerson, T. B., Stark, H., Atlas, E., Brioude, J., Fried, A., Holloway, J. S., Peischl, J., Richter, D., Walega, J., Weibring, P., Wollny, A. G., and Fehsenfeld, F. C.: Organic aerosol formation in urban and industrial plumes near Houston and Dallas, Texas, J. Geophys. Res.-Atmos., 114, D00F16, doi:10.1029/2008JD011493, 2009.

Benitez, F. J., Beltran-Heredia, J., Gonzalez, T., and Real, F.: UV photodegradation of phenolic aldehydes present in industrial wastewaters, J. Environ. Sci. Heal. A, 32, 2599-2612, 1997.

Blando, J. D. and Turpin, B. J.: Secondary organic aerosol formation in cloud and fog droplets: A literature evaluation of plausibility, Atmos. Environ., 34, 1623-1632, 2000.

Budavari, S., O’Neil, M. J., Simith, A., Heckelman, P. E., and Kinneary, J. F.: The Merck Index, 12th Edn., Merck \& Co., Inc., Whitehouse Station, NJ, 1996.

Buszewski, B. and Noga, S.: Hydrophilic interaction liquid chromatography (HILIC)-a powerful separation technique, Anal. Bioanal. Chem., 402, 231-247, 2012.

Carlton, A. G., Wiedinmyer, C., and Kroll, J. H.: A review of Secondary Organic Aerosol (SOA) formation from isoprene, Atmos. Chem. Phys., 9, 4987-5005, doi:10.5194/acp-9-4987-2009, 2009.

Cech, N. B., Krone, J. R., and Enke, C. G.: Predicting electrospray response from chromatographic retention time, Anal. Chem., 73, 208-213, 2001.

Chang, J. L. and Thompson, J. E.: Characterization of colored products formed during irradiation of aqueous solutions containing $\mathrm{H}_{2} \mathrm{O}_{2}$ and phenolic compounds, Atmos. Environ., 44, 541-551, 2010.

Clegg, S. L., Brimblecombe, P., and Wexler, A. S.: Thermodynamic model of the system $\mathrm{H}^{+}-\mathrm{NH}_{4}^{+}-\mathrm{SO}_{4}^{2-}-\mathrm{NO}_{3}^{-}-\mathrm{H}_{2} \mathrm{O}$ at tropospheric temperatures, J. Phys. Chem. A, 102, 2137-2154, 1998.

Coeur-Tourneur, C. C., Cassez, A., and Wenger, J. C.: Rate Coefficients for the Gas-Phase Reaction of Hydroxyl Radicals with 2-Methoxyphenol (Guaiacol) and Related Compounds, J. Phys. Chem. A, 114, 11645-11650, 2010.

Collett Jr, J. L., Herckes, P., Youngster, S., and Lee, T.: Processing of atmospheric organic matter by California radiation fogs, Atmos. Res., 87, 232-241, 2008.

Cubison, M. J., Ortega, A. M., Hayes, P. L., Farmer, D. K., Day, D., Lechner, M. J., Brune, W. H., Apel, E., Diskin, G. S., Fisher, J. A., Fuelberg, H. E., Hecobian, A., Knapp, D. J., Mikoviny, T., Riemer, D., Sachse, G. W., Sessions, W., Weber, R. J., Weinheimer, A. J., Wisthaler, A., and Jimenez, J. L.: Effects of aging on organic aerosol from open biomass burning smoke in aircraft and laboratory studies, Atmos. Chem. Phys., 11, 12049-12064, doi:10.5194/acp-11-12049-2011, 2011.

DeCarlo, P. F., Kimmel, J. R., Trimborn, A., Northway, M. J., Jayne, J. T., Aiken, A. C., Gonin, M., Fuhrer, K., Horvath, T., Docherty, K. S., Worsnop, D. R., and Jimenez, J. L.: Field-deployable, high-resolution, time-of-flight aerosol mass spectrometer, Anal. Chem., 78, 8281-8289, 2006.

de Gouw, J. and Jimenez, J. L.: Organic aerosols in the Earth's atmosphere, Environ. Sci. Technol., 43, 7614-7618, 2009.

Donahue, N. M., Robinson, A. L., Stanier, C. O., and Pandis, S. N.: Coupled partitioning, dilution, and chemical aging of semivolatile organics, Environ. Sci. Technol., 40, 2635-2643, 2006.

Dron, J., Zheng, W., Marchand, N., and Wortham, H.: New method to determine the total carbonyl functional group content in extractable particulate organic matter by tandem mass spectrometry, J. Mass Spectrom., 43, 1089-1098, 2008. 
Duplissy, J., Gysel, M., Sjogren, S., Meyer, N., Good, N., Kammermann, L., Michaud, V., Weigel, R., Martins dos Santos, S., Gruening, C., Villani, P., Laj, P., Sellegri, K., Metzger, A., McFiggans, G. B., Wehrle, G., Richter, R., Dommen, J., Ristovski, Z., Baltensperger, U., and Weingartner, E.: Intercomparison study of six HTDMAs: results and recommendations, Atmos. Meas. Tech., 2, 363-378, doi:10.5194/amt-2-363-2009, 2009.

Ervens, B., Turpin, B. J., and Weber, R. J.: Secondary organic aerosol formation in cloud droplets and aqueous particles (aqSOA): a review of laboratory, field and model studies, Atmos. Chem. Phys., 11, 11069-11102, doi:10.5194/acp-1111069-2011, 2011.

Ervens, B., Wang, Y., Eagar, J., Leaitch, W. R., Macdonald, A. M., Valsaraj, K. T., and Herckes, P.: Dissolved organic carbon (DOC) and select aldehydes in cloud and fog water: the role of the aqueous phase in impacting trace gas budgets, Atmos. Chem. Phys., 13, 5117-5135, doi:10.5194/acp-13-5117-2013, 2013.

Grieshop, A. P., Logue, J. M., Donahue, N. M., and Robinson, A. L.: Laboratory investigation of photochemical oxidation of organic aerosol from wood fires 1: measurement and simulation of organic aerosol evolution, Atmos. Chem. Phys., 9, 1263-1277, doi:10.5194/acp-9-1263-2009, 2009.

Hawthorne, S. B., Krieger, M. S., Miller, D. J., and Mathiason, M. B.: Collection and quantitation of methoxylated phenol tracers for atmospheric-pollution from residential wood stoves, Environ. Sci. Technol., 23, 470-475, 1989.

Heald, C. L., Jacob, D. J., Park, R. J., Russell, L. M., Huebert, B. J., Seinfeld, J. H., Liao, H., and Weber, R. J.: A large organic aerosol source in the free troposphere missing from current models, Geophys. Res. Lett., 32, L18809, doi:10.1029/2005GL023831, 2005.

Hennigan, C. J., Sullivan, A. P., Collett Jr, J. L., and Robinson, A. L.: Levoglucosan stability in biomass burning particles exposed to hydroxyl radicals, Geophys. Res. Lett., 37, L09806, doi:10.1029/2010g1043088, 2010.

Heringa, M. F., DeCarlo, P. F., Chirico, R., Tritscher, T., Dommen, J., Weingartner, E., Richter, R., Wehrle, G., Prévôt, A. S. H., and Baltensperger, U.: Investigations of primary and secondary particulate matter of different wood combustion appliances with a high-resolution time-of-flight aerosol mass spectrometer, Atmos. Chem. Phys., 11, 5945-5957, doi:10.5194/acp-11-59452011, 2011.

Hoffmann, D., Tilgner, A., Iinuma, Y., and Herrmann, H.: Atmospheric Stability of Levoglucosan: A Detailed Laboratory and Modeling Study, Environ. Sci. Technol., 44, 694-699, 2009.

Ip, H. S. S., Huang, X. H. H., and Yu, J. Z.: Effective Henry's law constants of glyoxal, glyoxylic acid, and glycolic acid, Geophys. Res. Lett., 36, L01802, doi:10.1029/2008GL036212, 2009.

Kroll, J. H. and Seinfeld, J. H.: Chemistry of secondary organic aerosol: Formation and evolution of low-volatility organics in the atmosphere, Atmos. Environ., 42, 3593-3624, 2008.

Lee, A. K. Y., Herckes, P., Leaitch, W. R., Macdonald, A. M., and Abbatt, J. P. D.: Aqueous OH oxidation of ambient organic aerosol and cloud water organics: Formation of highly oxidized products, Geophys. Res. Lett., 38, L11805, doi:10.1029/2011g1047439, 2011.

Lee, A. K. Y., Hayden, K. L., Herckes, P., Leaitch, W. R., Liggio, J., Macdonald, A. M., and Abbatt, J. P. D.: Characterization of aerosol and cloud water at a mountain site during WACS 2010: secondary organic aerosol formation through ox- idative cloud processing, Atmos. Chem. Phys., 12, 7103-7116, doi:10.5194/acp-12-7103-2012, 2012.

Li, Y. C. and Yu, J. Z.: Simultaneous determination of mono- and dicarboxylic acids, omega-oxo-carboxylic acids, midchain Ketocarboxylic acids, and aldehydes in atmospheric aerosol samples, Environ. Sci. Technol., 39, 7616-7624, 2005.

Li, Y. J., Chen, Q., Guzman, M. I., Chan, C. K., and Martin, S. T.: Second-generation products contribute substantially to the particle-phase organic material produced by $\beta$-caryophyllene ozonolysis, Atmos. Chem. Phys., 11, 121-132, doi:10.5194/acp11-121-2011, 2011a.

Li, Y. J., Yeung, J. W. T., Leung, T. P. I., Lau, A. P. S., and Chan, C. K.: Characterization of Organic Particles from Incense Burning Using an Aerodyne High-Resolution Time-of-Flight Aerosol Mass Spectrometer, Aerosol Sci. Tech., 46, 654-665, 2011b.

Liu, C. G., Zhang, P., Wang, Y. F., Yang, B., and Shu, J. N.: Heterogeneous Reactions of Particulate Methoxyphenols with $\mathrm{NO}_{3}$ Radicals: Kinetics, Products, and Mechanisms, Environ. Sci. Technol., 46, 13262-13269, 2012.

Massoli, P., Lambe, A. T., Ahern, A. T., Williams, L. R., Ehn, M., Mikkila, J., Canagaratna, M. R., Brune, W. H., Onasch, T. B., Jayne, J. T., Petaja, T., Kulmala, M., Laaksonen, A., Kolb, C. E., Davidovits, P., and Worsnop, D. R.: Relationship between aerosol oxidation level and hygroscopic properties of laboratory generated secondary organic aerosol (SOA) particles, Geophys. Res. Lett., 37, L24801, doi:10.1029/2010g1045258, 2010.

Middlebrook, A. M., Bahreini, R., Jimenez, J. L., and Canagaratna, M. R.: Evaluation of Composition-Dependent Collection Efficiencies for the Aerodyne Aerosol Mass Spectrometer using Field Data, Aerosol Sci. Tech., 46, 258-271, 2012.

Peng, C. G., Chow, A. H. L., and Chan, C. K.: Hygroscopic study of glucose, citric acid, and sorbitol using an electrodynamic balance: Comparison with UNIFAC predictions, Aerosol Sci. Tech., 35, 753-758, 2001.

Presto, A. A., Miracolo, M. A., Donahue, N. M., and Robinson, A. L.: Secondary Organic Aerosol Formation from High- $\mathrm{NO}_{\mathrm{x}}$ Photo-Oxidation of Low Volatility Precursors: n-Alkanes, Environ. Sci. Technol., 44, 2029-2034, 2010.

Roberts, G. C. and Nenes, A.: A continuous-flow streamwise thermal-gradient $\mathrm{CCN}$ chamber for atmospheric measurements, Aerosol Sci. Tech., 39, 206-221, 2005.

Robinson, A. L., Donahue, N. M., Shrivastava, M. K., Weitkamp, E. A., Sage, A. M., Grieshop, A. P., Lane, T. E., Pierce, J. R., and Pandis, S. N.: Rethinking organic aerosols: Semivolatile emissions and photochemical aging, Science, 315, 1259-1262, 2007.

Simoneit, B. R. T.: Biomass burning - A review of organic tracers for smoke from incomplete combustion, Appl. Geochem., 17, 129-162, 2002.

Sun, Y. L., Zhang, Q., Anastasio, C., and Sun, J.: Insights into secondary organic aerosol formed via aqueous-phase reactions of phenolic compounds based on high resolution mass spectrometry, Atmos. Chem. Phys., 10, 4809-4822, doi:10.5194/acp-104809-2010, 2010.

Sueper, D.: ToF-AMS data analysis software, http://cires.colorado. edu/jimenez-group/ToFAMSResources/ToFSoftware/index.html (last access: 1 June, 2012), 2012.

Wang, G. H., Chen, C. L., Li, J. J., Zhou, B. H., Xie, M. J., Hu, S. Y., Kawamura, K., and Chen, Y.: Molecular composition and size distribution of sugars, sugar-alcohols and carboxylic acids 
in airborne particles during a severe urban haze event caused by wheat straw burning, Atmos. Environ., 45, 2473-2479, 2011.

Warneck, P.: Chemistry of the natural atmosphere, 2nd Edn., Academic Press, San Diego, CA, 2000.

Warneck, P.: In-cloud chemistry opens pathway to the formation of oxalic acid in the marine atmosphere, Atmos. Environ., 37, 2423-2427, 2003.

Yaws, C. L.: Handbook of vapor pressure, volume 3, Organic compounds C8 to C28, Gulf Publishing Company, Houston, Texas, 1994.
Yee, L. D., Kautzman, K. E., Loza, C. L., Schilling, K. A., Coggon, M. M., Chhabra, P. S., Chan, M. N., Chan, A. W. H., Hersey, S. P., Crounse, J. D., Wennberg, P. O., Flagan, R. C., and Seinfeld, J. H.: Secondary organic aerosol formation from biomass burning intermediates: phenol and methoxyphenols, Atmos. Chem. Phys., 13, 8019-8043, doi:10.5194/acp-13-8019-2013, 2013.

Zhang, Q., Canagaratna, M. R., Jayne, J. T., Worsnop, D. R., and Jimenez, J. L.: Time- and size-resolved chemical composition of submicron particles in Pittsburgh: Implications for aerosol sources and processes, J. Geophys. Res.-Atmos., 110, D07S09, doi:10.1029/2004JD004649, 2005. 